\title{
Utilização de pimenta rosa como um aditivo natural na dieta sobre o desempenho de frangos de corte
}

\author{
Use of Brazilian red pepper as an additive natural on broilers performance
}

\author{
GONÇALVES, Fabiano Gomes ${ }^{1 *}$; ZANINI, Surama Freitas ${ }^{1}$; GUERRA, Ana Flávia \\ Quiles Garcia ${ }^{2}$; GONÇALVES, Elaine Paiva ${ }^{1}$; COLNAGO, Geraldo Luis ${ }^{1}$; FEITOSA, \\ Mariana Lourenção ${ }^{1}$
}

\author{
${ }^{1}$ Universidade Federal do Espírito Santo, Programa de Pós-Graduação em Ciências Veterinárias da \\ Alegre, Brasil. \\ ${ }^{2}$ Universidade Estadual de Maringá, Departamento de Zootecnia, Maringá, Paraná, Brasil. \\ *Endereço para correspondência: f.gomes.goncalves@bol.com.br
}

\section{RESUMO}

Objetivou-se a utilização do farelo de pimenta rosa (FPR) como um aditivo natural na dieta sobre o desempenho de frangos. Utilizaram-se 396 pintos machos, Cobb de um dia de idade distribuídos em um delineamento inteiramente casualizado com três tratamentos e seis repetições, com 22 aves por unidade experimental, constituídos pelos grupos controle negativo $(\mathrm{CN})$; controle positivo $(\mathrm{CP})$ e dieta com 1,2\% FPR. Quanto à composição química do FPR verificou-se que os teores de extrato etéreo, fibra bruta, cálcio, fenóis totais, taninos totais e taninos condensados foram superiores aos encontrados no milho, sendo que os demais nutrientes como a proteína bruta e o fósforo tiveram valores próximos aos observados neste grão. Não houve diferença significativa entres os tratamentos no desempenho animal. $\mathrm{O}$ FPR reduziu significativamente as concentrações das enzimas alanina aminotransferase (ALT) e gama glutamiltransferase (GGT) aos 21 e 41 dias de idade, respectivamente, comparado ao $\mathrm{CN}$, sem comprometer o ganho de peso. Esta redução sugeriu uma diminuição de síntese protéica provavelmente em função de uma menor absorção de aminoácidos. Concluiu-se que a composição química-bromatológica do farelo de pimenta rosa se assemelha a do milho exceto pelo conteúdo de fibra, extrato etéreo, cálcio e compostos fenólicos, sendo que a adição de $1,2 \%$ de farelo de pimenta rosa na dieta reduziu os níveis séricos de ALT e GGT sem interferir no desempenho animal.

Palavras-chave: aroeira-vermelha, enzimas hepáticas, taninos

\section{SUMMARY}

The aim was to evaluate the use of Brazilian red pepper meal (BRPM) as an additive natural in feed on performance of broilers. A total of 396 day-old male chicks, Cobb, distributed in a randomized design in groups of three treatments and six replicates of 22 broilers each, consisting of the negative control - basal diet without growth promoter or brazilian red pepper; positive control - diet with zinc bacitracin and salinomycin; diet with 1.2\% BRPM. Regarding the chemical composition of the BRPM it was verified that the ether extract, crude fiber, calcium, total phenolics, total and condensed tannins were higher than in corn, although other nutrients such as protein and phosphorus have values close those observed in this grain. There was no significant difference between treatments on animal performance. The BRPM reduced significantly the concentrations of alanine aminotransferase and gamma glutamyltransferase enzymes at 21 and 41 days old, respectively, compared to the $\mathrm{CN}$, without compromising the weight gain. This reduction suggested a decrease of protein synthesis probably due to a lower absorption of aminoacids. It was concluded that the utilization of $1.2 \%$ of BRPM did not reduce the animal performance.

Keywords: Brazilian red pepper, hepatic enzymes, tannins 


\section{INTRODUÇÃO}

A avicultura brasileira encontra-se em posição de destaque como o maior exportador e o terceiro maior produtor de carne de frango. Este crescimento ocorreu em função de melhoria nas áreas de genética, manejo, sanidade e alimentação impulsionada pelo uso dos antibióticos.

A União Européia que é a segunda maior importadora de carne de frango brasileira (UBABEF, 2013), proibiu qualquer tipo de antibiótico e quimioterápico como promotor de crescimento na produção animal. Assim, há uma demanda em encontrar produtos alternativos para prevenir a ocorrência de doenças e ao mesmo tempo garantir um maior desempenho animal, já que a retirada total dos promotores de crescimento pode resultar em queda na lucratividade do setor, pela redução no desempenho de 3 a 7\% e aumento na mortalidade (TOLEDO et al., 2007).

Dentre estas opções encontram-se os fitoquímicos que embora sejam uma opção frente aos índices de resistência bacteriana dos fármacos existentes (KHULLAR, 2010), devem ser melhor avaliados, pois dependendo da quantidade ingerida, podem causar danos ao fígado (MINCIS \& MINCIS, 2007). A dosagem das enzimas alanina aminotransferase (ALT), aspartato aminotransferase (AST) e gama glutamiltransferase (GGT) são ferramentas essenciais para o diagnóstico de lesões hepáticas (SCHMIDT et al., 2007). Dessa forma, um aumento na atividade destas enzimas pode indicar uma toxicidade por drogas ou infecções no fígado.

Em meio a inúmeras espécies de plantas com propriedades medicinais, especialmente atividade antimicrobiana, a literatura cita Schinus terebinthifolius popularmente conhecida como aroeira- vermelha (AMORIM \& SANTOS, 2003). Seu fruto é conhecido como pimenta rosa que tanto pode ser comercializado in natura ou na forma de óleo essencial, este gera um subproduto gerado pela extração do óleo assim como de frutos refugados para comercialização que pode ser alternativa para a alimentação animal. Lima et al. (2006) e Zanini et al. (2009) observaram a presença de compostos fenólicos como os taninos, além de alcalóides, saponinas, esteróis e terpenos na Schinus terebinthifolius Raddi. Os taninos são compostos fenólicos que têm capacidade de se combinar com as enzimas digestivas, proteínas e outros polímeros (carboidratos e pectinas) formando complexos estáveis, impedindo a absorção dos nutrientes (COSTA et al., 2008). Objetivou-se avaliar a composição químico-bromatológica do farelo de pimenta rosa e sua utilização na dieta de frangos de corte.

\section{MATERIAL E MÉTODOS}

O experimento foi conduzido no Setor de Aves do Instituto Federal do Espírito Santo no município de Alegre na região sul do estado do Espírito Santo situado a $20^{\circ} 45^{\prime} 48^{\prime \prime}$ de latitude Sul e $41^{\circ} 31^{\prime} 57^{\prime \prime}$ de longitude oeste e altitude de 144 metros. O clima predominante é quente e úmido no verão e seco no inverno. No período experimental as temperaturas mínimas e máximas no interior do galpão foram de $24^{\circ} \mathrm{C}$ e $36^{\circ} \mathrm{C}$, respectivamente.

Foram utilizados 396 pintos de corte da linhagem Cobb, machos, alojados em 18 boxes de $2 \mathrm{~m}^{2}$ cada, durante $\mathrm{o}$ período de 1 - 41 dias de idade e distribuídos em um delineamento inteiramente casualizado em grupos de três tratamentos e seis repetições, constituídos pelo Controle Negativo 
(CN) - Dieta basal sem promotor de crescimento e sem farelo de pimenta rosa; Controle positivo (CP) - Dieta com antibiótico bacitracina de zinco $15 \% \quad(45 \mathrm{mg} / \mathrm{kg})$ e salinomicina $12 \%$ $(67 \mathrm{mg} / \mathrm{kg})$; Dieta com 1,2\% (12g/kg) de farelo de pimenta rosa. Estudos anteriores demonstraram que o farelo de pimenta rosa não afetou o desempenho das aves com a adição de até 1,2\% (GONÇALVES et al., 2012).
No período de 1 a 21 dias de idade os animais foram criados com uma ração inicial com $22 \%$ de PB e $3000 \mathrm{Kcal}$ $\mathrm{EM} / \mathrm{kg}$. Do $22^{-}$ao $41^{\circ}$ dia de idade as aves foram alimentadas com a ração de crescimento/terminação com 19\% PB e $3100 \mathrm{kcal} \mathrm{EM} / \mathrm{kg}$ à base de milho e soja (Tabela 1), segundo o manual da linhagem.

Tabela 1. Composição centesimal e química das rações basais experimentais

\begin{tabular}{|c|c|c|}
\hline \multirow{2}{*}{ Ingredientes (\%) } & \multicolumn{2}{|c|}{ Fases } \\
\hline & Inicial $(1-22$ dias $)$ & Crescimento (23-41 dias) \\
\hline Milho Moído & 54,20 & 62,82 \\
\hline Farelo de soja & 38,00 & 31,00 \\
\hline Óleo de soja & 3,99 & 3,00 \\
\hline Fosfato Bicálcico & 1,83 & 1,60 \\
\hline Calcário & 1,00 & 0,80 \\
\hline Sal & 0,42 & 0,40 \\
\hline $\mathrm{DL}$ - metionina & 0,27 & 0,20 \\
\hline L-lisina & 0,15 & 0,06 \\
\hline Sup. Vitamínico ${ }^{1}$ & 0,04 & 0,03 \\
\hline Sup. Mineral ${ }^{2}$ & 0,05 & 0,04 \\
\hline Colina & 0,06 & 0,04 \\
\hline BHT & 0,01 & 0,01 \\
\hline Total & 100 & 100 \\
\hline \multicolumn{3}{|c|}{ Composição calculada } \\
\hline $\mathrm{EM}(\mathrm{Kcal} / \mathrm{Kg})$ & 3.000 & 3.100 \\
\hline Proteína Bruta $(\mathrm{g} / \mathrm{kg})$ & 220 & 190 \\
\hline Extrato Etéreo $(\mathrm{g} / \mathrm{kg})$ & 6,20 & 5,50 \\
\hline Matéria Mineral (\%) & 6,00 & 5,30 \\
\hline Cálcio (\%) & 0,95 & 0,80 \\
\hline Fósforo disponível (\%) & 0,45 & 0,40 \\
\hline Fibra Bruta $(\%)$ & 4,00 & 3,70 \\
\hline \multicolumn{3}{|c|}{ Aminoácidos totais } \\
\hline Lisina (\%) & 1,30 & 1,05 \\
\hline Metionina (\%) & 0,60 & 0,51 \\
\hline Met. + Cist. (\%) & 0,99 & 0,85 \\
\hline Treonina $(\%)$ & 0,82 & 0,73 \\
\hline Triptofano (\%) & 0,28 & 0,24 \\
\hline \multicolumn{3}{|c|}{ 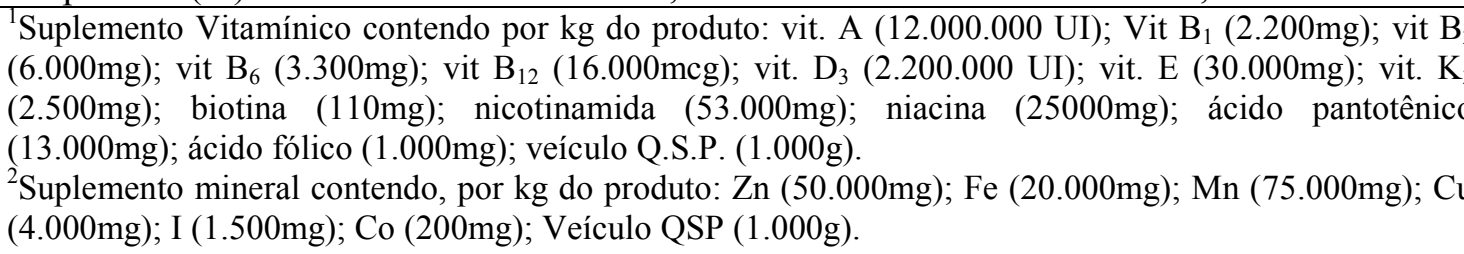 } \\
\hline
\end{tabular}


Foi determinada a composição químicabromatológica do farelo de pimenta rosa, obtido de frutos maduros sem a extração do óleo, de acordo com a metodologia de Queiroz \& Silva (2006). Os teores de taninos do farelo e das rações experimentais foram determinados com base nos trabalhos de Porter et al. (1986), Dawra et al. (1988), Inoue \& Hagerman (1988) e Makkar et al. (1993). $\mathrm{O}$ manejo utilizado foi $\mathrm{o}$ tradicionalmente empregado nas granjas comerciais, com água e ração, na forma farelada, fornecidas a vontade durante todo o período experimental. $\mathrm{Na}$ tentativa de proporcionar um desafio sanitário, utilizou-se $30 \%$ de cama reutilizada de casca de café. Os parâmetros de desempenho avaliados foram: peso inicial, peso final, ganho médio de peso, consumo médio de ração, conversão alimentar, viabilidade e fator de produção.

Aos 21 e 41 dias de idade, 10 animais de cada tratamento foram escolhidos aleatoriamente e colhido amostras de sangue por meio de punção da veia ulnar (CASTRO et al., 2010). Após a colheita, as amostras foram imediatamente centrifugadas para obtenção de soro com a utilização de centrífuga da marca Excelsa, modelo Fanem ${ }^{\circledR}$ a 2000 xg durante $10 \mathrm{~min}$. As amostras de soro foram congeladas a $-20^{\circ} \mathrm{C}$ até o momento da realização das análises. Foram dosadas as enzimas alanina aminotransferase (ALT), aspartato aminotransferase (AST) e gama glutamiltransferase (GGT) em um analisador semi-automático (TP Analyzer Plus ${ }^{\circledR}$, Thermoplate) usando kit comercial (Labtest ${ }^{\circledR}$ Diagnóstica S.A. Lagoa Santa - MG - Brasil).

Os resultados foram submetidos à análise de variância e, quando significativo, as médias foram comparadas pelo teste de Student Newman Keuls $(\mathrm{P}<0,05)$ com a utilização do programa SAEG (Sistema para Análises Estatísticas e Genéticas) versão 5,0 (UFV, 2007).

\section{RESULTADOS E DISCUSSÃO}

A avaliação nutricional dos ingredientes possibilita a otimização na formulação das dietas animais visando atender os requerimentos nutricionais, aliado a um menor custo. Dessa forma a determinação da composição química-bromatológica do farelo de pimenta rosa é de grande importância a fim de melhorar o desempenho sem afetar a saúde dos animais.

Quanto à composição química verificou-se que os teores de extrato etéreo, fibra bruta, cálcio, fenóis totais, taninos totais e taninos condensados foram superiores aos encontrados no milho (GOBESSO et al., 2008; ROSTANGO et al., 2011), sendo que os demais nutrientes como a proteína bruta e o fósforo tiveram valores próximos aos observados neste grão, que justificou a utilização de farelo de aroeira-vermelha como um aditivo natural na alimentação de frangos de corte (Tabela 2 e 3). O alto teor de extrato etéreo deve-se a presença de óleos voláteis que pode constituir em uma vantagem deste subproduto, pois representa os óleos essenciais que estão relacionados com diversas funções necessárias à sobrevivência vegetal, exercendo papel fundamental na defesa contra microrganismos (SIQUI et al., 2000).

Os teores de fenóis totais e taninos totais foram de 2,864\% e 2,494\% (equivalente de ácido tânico em gramas por $100 \mathrm{~g}$ ), respectivamente, e os taninos condensados de $0,187 \%$ (equivalente de leucocianidina em gramas por $100 \mathrm{~g}$ ) no farelo de pimenta rosa (Tabela 3). Os compostos fenólicos são substâncias com elevada propriedade antioxidante, 
por possuir propriedades redutoras em suas estruturas (POVH et al., 2012).

A inclusão de ingredientes que contém taninos nas rações de frangos de corte deve ser feita com cautela, um exemplo é o sorgo que, embora possa substituir até $100 \%$ do milho, por apresentarem composições químicas semelhantes, tende a diminuir as respostas de desempenho produtivo, em função do seu teor de tanino condensado (SILVA et al., 2009).
De acordo com Teixeira (2001) grãos com teores de taninos condensados superiores a $1 \%$ podem diminuir a digestibilidade de metionina, aminoácido limitante ao desenvolvimento de aves. $\mathrm{Na}$ presente pesquisa, os valores de taninos condensados na dieta com farelo de pimenta rosa não ultrapassaram $1 \%$ (Tabela 3) e desta forma não interferiu negativamente no desempenho das aves (Tabela 4).

Tabela 2. Composição químico-bromatológica do farelo de pimenta rosa

\begin{tabular}{lc}
\hline Composição química-bromatológica & Resultados $(\mathrm{g} / 100 \mathrm{~g})$ \\
\hline Matéria Seca & 87,10 \\
Umidade & 12,90 \\
Proteína Bruta & 7,10 \\
Extrato Etéreo & 9,74 \\
Matéria Mineral & 3,53 \\
Cálcio & 1,12 \\
Fósforo & 0,33 \\
Fibra Bruta & 21,35 \\
Fibra em detergente ácido (FDA) & 22,94 \\
Fibra em detergente neutro (FDN) & 45,05 \\
\hline
\end{tabular}

Tabela 3. Quantificação e qualificação de Compostos Fenólicos (CF): Fenóis Totais (FT), Taninos Totais (TT) e Taninos Condensados (TC) no farelo de pimenta rosa e nas dietas experimentais

\begin{tabular}{|c|c|c|c|c|c|c|c|}
\hline \multirow{3}{*}{ CF $(\%)$} & \multirow{3}{*}{$\begin{array}{c}\text { Farelo } \\
\text { Pimenta } \\
\text { Rosa }\end{array}$} & \multirow{2}{*}{\multicolumn{3}{|c|}{$\begin{array}{c}\text { Ração Inicial } \\
\text { Tratamentos }^{(1)} \\
\end{array}$}} & \multirow{2}{*}{\multicolumn{3}{|c|}{$\begin{array}{c}\text { Ração Crescimento } \\
\text { Tratamentos }^{(1)} \\
\end{array}$}} \\
\hline & & & & & & & \\
\hline & & 1 & 2 & 3 & 1 & 2 & 3 \\
\hline FT $\left(\right.$ EgAT/100 g) ${ }^{(2)}$ & 2,864 & 0,301 & 0,257 & 0,334 & 0,255 & 0,331 & 0,420 \\
\hline $\mathrm{TT}(\mathrm{EgAT} / 100 \mathrm{~g})^{(2)}$ & 2,494 & 0,179 & 0,134 & 0,289 & 0,144 & 0,188 & 0,276 \\
\hline TC (EgELEU/100 g) ${ }^{(3)}$ & 0,187 & 0,004 & 0,004 & 0,01 & 0,003 & 0,003 & 0,009 \\
\hline
\end{tabular}

${ }^{(1)}$ Tratamentos: 1- Controle Negativo - Ração basal sem antibiótico e sem farelo de pimenta rosa; 2 Controle Positivo - Ração com bacitracina de zinco 15\% (45mg/kg) e salinomicina $12 \%$ (67mg/kg); 3 Ração com $1,2 \%(12 \mathrm{~g} / \mathrm{kg})$ de farelo de pimenta rosa.

${ }^{(2)}$ Valores expressos em equivalente grama de ácido tânico por $100 \mathrm{~g}$ de MS.

${ }^{(3)}$ Valores expressos em equivalente grama de leucocianidina por $100 \mathrm{~g}$ de MS. 
Tabela 4. Desempenho de frangos de corte tratados com farelo de pimenta rosa e com ou sem antibióticos

\begin{tabular}{|c|c|c|c|c|c|c|c|}
\hline \multicolumn{8}{|c|}{ Peso da Ave $(\mathrm{g})^{\mathrm{ns}}$} \\
\hline \multirow{2}{*}{ Tratamento } & \multicolumn{7}{|c|}{ Período (dias) } \\
\hline & 7 & 14 & \multicolumn{2}{|l|}{21} & 28 & 35 & 41 \\
\hline $\mathrm{CN}^{1}$ & $158 \pm 11$ & $385 \pm 30$ & \multicolumn{2}{|c|}{$709 \pm 45$} & $1193 \pm 61$ & $1832 \pm 91$ & $2369 \pm 150$ \\
\hline $\mathrm{CP}^{2}$ & $157 \pm 5$ & $384 \pm 11$ & \multicolumn{2}{|c|}{$707 \pm 59$} & $1198 \pm 87$ & $1845 \pm 107$ & $2340 \pm 165$ \\
\hline $1,2 \% \mathrm{FPR}^{3}$ & $154 \pm 5$ & $373 \pm 8$ & \multicolumn{2}{|c|}{$682 \pm 41$} & $1163 \pm 57$ & $1784 \pm 74$ & $2292 \pm 152$ \\
\hline \multicolumn{8}{|c|}{ Ganho de Peso da Ave $(\mathrm{g})^{\mathrm{ns}}$} \\
\hline & 1 a 7 & 1 a 14 & \multicolumn{2}{|c|}{1 a $21 \quad 1$ a 28} & 1 a 35 & 1 a 41 & 22 a 41 \\
\hline $\mathrm{CN}$ & $108 \pm 11$ & $335 \pm 30$ & $658 \pm 45$ & $1143 \pm 61$ & $1782 \pm 91$ & $2318 \pm 150$ & $1638 \pm 146$ \\
\hline $\mathrm{CP}$ & $107 \pm 5$ & $333 \pm 11$ & $656 \pm 59$ & $1148 \pm 87$ & $1795 \pm 107$ & $2289 \pm 165$ & $1633 \pm 123$ \\
\hline $1,2 \%$ FPR & $103 \pm 5$ & $322 \pm 8$ & $632 \pm 41$ & $1113 \pm 57$ & $1734 \pm 75$ & $2241 \pm 152$ & $1610 \pm 132$ \\
\hline \multicolumn{8}{|c|}{ Consumo por Ave(g) ${ }^{\mathrm{ns}}$} \\
\hline $\mathrm{CN}$ & $136 \pm 10$ & $504 \pm 27$ & $1131 \pm 45$ & $2012 \pm 76$ & $3304 \pm 155$ & $4487 \pm 287$ & $3312 \pm 191$ \\
\hline $\mathrm{CP}$ & $136 \pm 4$ & $492 \pm 7$ & $1102 \pm 61$ & $1971 \pm 103$ & $3164 \pm 104$ & $4394 \pm 209$ & $3299 \pm 247$ \\
\hline $1,2 \%$ FPR & $133 \pm 5$ & $490 \pm 20$ & $1089 \pm 17$ & $1970 \pm 119$ & $3207 \pm 92$ & $4387 \pm 155$ & $3292 \pm 162$ \\
\hline \multicolumn{8}{|c|}{ Conversão Alimentar $(\mathrm{g} / \mathrm{g})^{\mathrm{ns}}$} \\
\hline $\mathrm{CN}$ & $1,26 \pm 0,04$ & $1,51 \pm 0,09$ & $1,74 \pm 0,13$ & $1,78 \pm 0,08$ & $1,87 \pm 0,11$ & $1,94 \pm 0,08$ & $2,03 \pm 0,12$ \\
\hline $\mathrm{CP}$ & $1,29 \pm 0,09$ & $1,48 \pm 0,03$ & $1,69 \pm 0,17$ & $1,72 \pm 0,11$ & $1,77 \pm 0,11$ & $1,93 \pm 0,16$ & $2,03 \pm 0,22$ \\
\hline $1,2 \%$ FPR & $1,29 \pm 0,03$ & $1,53 \pm 0,06$ & $1,73 \pm 0,09$ & $1,76 \pm 0,13$ & $1,86 \pm 0,07$ & $1,96 \pm 0,08$ & $2,05 \pm 0,09$ \\
\hline & \multicolumn{4}{|c|}{ Viabilidade (\%) ${ }^{\text {ns }}$} & \multicolumn{3}{|c|}{ Fator de Produção ns } \\
\hline $\mathrm{CN}$ & \multicolumn{4}{|c|}{$90,9 \pm 7$} & \multicolumn{3}{|c|}{$270,12 \pm 18$} \\
\hline $\mathrm{CP}$ & \multicolumn{4}{|c|}{$91,7 \pm 9,7$} & \\
\hline $1,2 \%$ FPR & \multicolumn{4}{|c|}{$924+37$} & & \multicolumn{2}{|l|}{$\begin{array}{l}276,02 \pm 60 \\
26380 \pm 27\end{array}$} \\
\hline
\end{tabular}

${ }^{\mathrm{ns}}$ Efeito não significativo, pelo teste de SNK $(\mathrm{P}<0,05)$.

Tratamentos: 1 - Controle Negativo - Ração basal sem antibiótico e sem farelo de pimenta rosa; 2 Controle Positivo - Ração com bacitracina de zinco 15\% (45 mg/kg) e salinomicina 12\% (67 mg/kg); 3 Ração com 1,2\% (12 g/kg) de farelo de pimenta rosa.

Não houve diferença significativa entres os tratamentos para os parâmetros avaliados $(\mathrm{P}>0,05)$. Estes resultados indicam que, embora as aves tenham sido alojadas com $30 \%$ de cama reutilizada esta estratégia não foi suficiente para proporcionar um desafio sanitário capaz de permitir verificar diferenças entre os grupos tratados ou não com antibiótico $(\mathrm{P}>0,05)$. Em um estudo, Souza et al. (2010), concluíram que as respostas aos antibióticos nas rações de frangos de corte foram inferiores comparadas ao controle.

Os antibióticos promotores de crescimento apresentam resultados satisfatórios em plantéis criados em instalações de alto endemismo. Por outro lado, no desempenho de animais criados em condições ambientais, sanitárias e nutricionais adequados, o uso de antibióticos promotores de crescimento não traz melhorias, o efeito benéfico dos antibióticos é maior em condições de campo do que em estações experimentais devido à presença de doenças e às diferenças de higiene e estresse. Estes benefícios também são maiores em condições de elevado densidade populacional (TOLEDO et al., 2007). Além disso, o uso concomitante de antibióticos pode 
causar aumento de patógenos devido a resistência bacteriana (SALEHA et al., 2009).

A inclusão do farelo de pimenta rosa não trouxe prejuízos no desempenho dos animais (Tabela 4) comparado a utilização de promotor de crescimento, provavelmente por se tratar de um ingrediente que apresenta uma composição nutricional semelhante ao do milho exceto pelo seu conteúdo em fibra, extrato etéreo, cálcio e compostos fenólicos. Resultados anteriores haviam demonstrado que o farelo de pimenta rosa não afetou o desempenho das aves com adição de até 1,2\% (GONÇALVES et al., 2012), porém pode atuar de maneira eficaz na melhoria das vilosidades intestinais (ZANINI et al., 2011), podendo promover uma melhoria na superfície intestinal quando comparada a aves sem promotor de crescimento (SILVA et al., 2011). Portanto, a utilização deste subproduto pode ser uma alternativa na utilização de aditivos naturais, substituindo os promotores de crescimento, além de minimizar o impacto ambiental e reduzir o custo final de produção.
Em relação aos resultados obtidos para as variáveis de viabilidade e fator de produção (Tabela 4), não foram observadas diferenças significativa entre os tratamentos $(\mathrm{P}>0,05)$. Ortiz et al. (1994) avaliaram dietas com adição de ácido tânico em frangos de corte, nos níveis $0 ; 8$ e $16 \mathrm{~g} / \mathrm{kg}$ de ração, verificando um aumento da mortalidade de aves de 33 e $50 \%$ com 8 e $16 \mathrm{~g}$ de acido tânico, respectivamente, ligada a significativa redução no ganho de peso, consumo de ração e conversão alimentar.

Os valores médios dos níveis séricos das enzimas AST, encontram-se próximos aos observados por Borsa et al. (2006) que foram 202-325, 14-34 e 9-17 UI/L aos 21 dias e 202-229, 4-14 e 17-24 UI/L aos 42 dias para AST, ALT e GGT, respectivamente para frangos de corte clinicamente saudáveis. De um modo geral, as variações nos níveis séricos das enzimas estudadas em relação aos resultados encontrados por outros autores podem estar relacionados a vários fatores como o estado de saúde das aves, idade, tipo de alimentação, manejo, kits comerciais e aparelhagem utilizada na dosagem (Tabela 5).

Tabela 5. Valores médios e desvios padrões dos níveis das enzimas alaninaaminotransferase (ALT), aspartato aminotransferase (AST) e gama glutamiltransferase (GGT) em frangos de corte tratados com farelo de pimenta rosa e com ou sem antibióticos

\begin{tabular}{|c|c|c|c|c|c|c|}
\hline \multirow{2}{*}{ Tratamentos } & \multicolumn{3}{|c|}{ Enzimas (UI/L) no $21^{\circ}$ dia de idade } & \multicolumn{3}{|c|}{ Enzimas (UI/L) no $41^{\circ}$ dia de idade } \\
\hline & $\mathrm{AST}^{\mathrm{ns}}$ & ALT & $\mathrm{GGT}^{\mathrm{ns}}$ & $\mathrm{AST}^{\mathrm{ns}}$ & $\mathrm{ALT}^{\mathrm{ns}}$ & GGT \\
\hline $\mathrm{CN}^{1}$ & $192,19 \pm 29,16$ & $8,70 \pm 2,97^{\mathrm{a}}$ & $11,32 \pm 3,83$ & $251,6 \pm 78,09$ & $4,72 \pm 1,58$ & $20,09 \pm 6,46^{\mathrm{a}}$ \\
\hline $\mathrm{CP}^{2}$ & $197,16 \pm 41,85$ & $7,11 \pm 1,04^{\mathrm{a}}$ & $13,37 \pm 2,26$ & $280,36 \pm 50,46$ & $4,88 \pm 1,70$ & $14,59 \pm 3,15^{b}$ \\
\hline $1,2 \% \mathrm{FPR}^{3}$ & $179,39 \pm 10,21$ & $4,58 \pm 2,53^{\mathrm{b}}$ & $14,75 \pm 3,25$ & $237,54 \pm 31,99$ & $4,37 \pm 1,57$ & $14,46 \pm 3,22^{b}$ \\
\hline
\end{tabular}

${ }^{\mathrm{ab}}$ Médias seguidas por letras distintas na mesma coluna diferem significativamente pelo teste SNK $(\mathrm{P}<0,05)$.

${ }^{\mathrm{ns}}$ Efeito não significativo, pelo teste de $\mathrm{SNK}(\mathrm{P}<0,05$.

Tratamentos: 1 - Controle Negativo: Ração basal sem antibiótico e sem farelo de pimenta rosa; 2 Controle Positivo: Ração com bacitracina de zinco 15\% (45mg/kg) e salinomicina12\% (67mg/kg); 3 Ração com $1,2 \%(12 \mathrm{~g} / \mathrm{kg})$ de farelo de pimenta rosa. 
Aos 21 e 41 dias de idade, os valores séricos da AST não foram influenciados pelos tratamentos $(\mathrm{P}>0,05)$. Quanto aos valores de ALT, verificou-se aos 21 dias de idade influência dos tratamentos, sendo que a utilização de farelo de pimenta rosa reduziu significativamente seu nível comparado aos demais tratamentos $(\mathrm{P}<0,05)$. Este efeito é geralmente observado quando há redução do potencial de síntese hepática a qual pode ser causada pela ação dos taninos.

Utilizando farelo de pimenta rosa associado ou não a antibióticos para frangos de corte, Gonçalves et al. (2012), observaram efeito dos tratamentos sobre a dosagem da AST aos 21 dias de Idade para as aves suplementadas com FPR associado com as mais altas doses de antibióticos (33-45mg kg-1 de bacitracina de zinco $+51-67 \mathrm{mg} \mathrm{kg-1} \mathrm{de}$ salinomicina) com maiores valores de AST, comparado aos demais tratamentos. Já para a dosagem de ALT foram maiores nos animais alimentados com farelo de pimenta rosa comparado aos tratamentos com o farelo de pimenta rosa combinado com o uso de antibióticos aos 21 dias de idade, entretanto aos 41 dias não foram observados efeitos entre os tratamentos para estas variáveis.

Os taninos são considerados fatores antinutricionais, pela habilidade de complexar com proteínas (SHAHIDI \& NACZK, 1995) e limitar o aporte nutricional para a síntese proteica. De acordo com Teixeira (2001) o nível de tanino condensado de até $1 \%$ não promove redução de peso, o que também não ocorreu neste experimento. Ademais, os níveis de ALT, reduziram conforme a idade, não difererindo $(\mathrm{P}>0.05)$ entre os tratamentos aos 41 dias, concordando com Gonçalves et al, (2012). Portanto, embora tenha sido observada redução da ALT pela adição do farelo de pimenta rosa, não houve redução do ganho de peso (Tabela 4).

Em relação aos valores de GGT, não foi observado efeito significativo dos tratamentos aos 21 dias de idade $(\mathrm{P}>0.05)$ somente aos 41 dias de idade $(\mathrm{P}<0,05)$. Embora o grupo tratado com antibiótico ou com farelo de pimenta rosa tenha apresentado os menores valores de GGT, sugerindo uma redução da síntese hepática, não houve queda no ganho de peso (Tabela 4). O grupo $\mathrm{CN}$ apresentou o maior valor médio de GGT comparado aos demais tratamentos, contudo, isto não significa que tenha ocorrido alguma lesão hepatobiliar tendo em vista que esse valor está dentro da média observada por Borsa et al. (2006) e Traesel (2011).

Nas condições em que o experimento foi desenvolvido concluiu-se que a adição de $1,2 \%$ de farelo de pimenta rosa na dieta reduziu os níveis séricos de ALT e GGT sem interferir no desempenho animal, podendo, portanto, ser utilizado como aditivo nas rações de frangos de corte.

\section{AGRADECIMENTOS}

Ao $\mathrm{CNPq}$ pelo apoio financeiro concedido para execução desta pesquisa.

\section{REFERÊNCIAS}

AMORIM, M.M.R.; SANTOS, L.C. Treatment of Bacterial Vaginosis with Schinus terebinthifolius Raddi Vaginal Gel: a Randomized Controlled Trial. Revista Brasileira de Ginecologia e Obstetrícia, v.25, n.2, p.95-102, 2003. 
BORSA, A.; KOHAYAGAWA, A.; BORETTI, L.P.; SAITO, M.E.;

KUIBIDA, K. Serum levels of hepatic enzyme function in clinically healthy broiler chickens. Arquivo Brasileiro de Medicina Veterinária e Zootecnia, v.58, n.4, p.675-677, 2006.

CASTRO, A.G.M.; LUCIANO, R.L.; KANASHIRO, A.M.I,; CARDOSO, A.L.S.P.; TESSARI, E.N.C. Manual veterinário de colheita e envio de amostras. Rio de Janeiro: Organização Pan-Americana da Saúde, 2010. p.144173.

COSTA, C.T.C.; BEVILAQUA, C.M.L.; MORAES, S.M.; VIEIRA, L.S. Tannins and their use in small ruminants. Revista Brasileira de Plantas Medicinais, v.10, n.4, p.108116, 2008.

DAWRA, R.K.; MAKKAR, H.P.S.; SINGH, B. Protein-binding capacity of microquantities of tannins. Analytical Biochemistry, v.170, p.50-53, 1988.

FIALHO, E.T.; PINTO, H. Utilização de sorgo em rações para suínos e aves. Concórdia, SC: EMBRAPA, 1992. p.4-19. (Circular técnica, 16).

GOBESSO, A.A.O.; D`AURIA, E.; RENNÓ, L.S.; RENNÓ, F.P.

Replacement of corn by ground or extruded sorghum in diets for horses.

Revista Brasileira de Zootecnia, v.37, n.11, p.2011-2016, 2008.

GONÇALVES, F.G.; ZANINI, F.S.; FEITOSA, M.L.; GONÇALVES, E.P.M.; COLNAGO, G.L. Effect of Brazilian red pepper meal associated with different levels of antibiotics on broilers chickens. Ciência Rural, v.42, p.1503-1509, 2012.
INOUE, K.H.; HAGERMAN, A.E.

Determination of gallotannin with rhodanine. Analytical Biochemistry, v.169, p.363-369, 1988.

KHULLAR, N. Antimicrobials from plants and their use in therapeutics and drug discovery. IIOAB Journal, v.1, n.3, p.31-37, 2010.

LIMA, M.R.F.; XIMENES, E.C.P.A.; LUNA, J.S.; SANT'ANA, A.E.G. The antibiotic activity of some Brazilian medicinal plants. Revista Brasileira de Farmacognosia, v.16, p.300-306, 2006.

MAKKAR, H.P.S.; BLUMMEL M.; BOROWY, N.K.; BECKER, K.

Gravimetric determination of tannins and their correlation with chemical and protein precipitation methods. Journal of the Science of Food and Agriculture, v.61, p.161-165, 1993.

MINCIS, M.; MINCIS, R. Doenças hepáticas: por que são importantes para o estudo de doenças do fígado. Prática Hospitalar, v.9, n.51, p.44-48, 2007.

ORTIZ, L.T.; ALZUETA, C.; TREVINO, J. Effects off aba bean tannins on the growth and histological struture of the intestinal tract and liver of chicks and rats. British Poultry Science, v.35, n.5, p.743-754, 1994.

PORTER, L.J.; HRSTICH, L.N.; CHAN, B.G. The conversion of procyanidins and prodelphinidins to cyanidin and delphinidin.

Phytochemistry, v.25, p.223-230, 1986.

POVH, J.A.; SANTOS, F.B.; SILVA, K.R. Total Phenols and Flavonoids in four species of the Genus Hyptis Jacq. occurring in cerrado. Brazilian

Geographical Journal: Geosciences and Humanities Research Medium, v.3, n.2, p.520-528, 2012. 
QUEIROZ, A.C.; SILVA, D.J. Análise de alimentos: métodos químicos e biológicos. 3.ed. Viçosa: Universidade Federal de Viçosa, 20006. 235p.

ROSTAGNO, H.S.; ALBINO, L.F.T.; DONZELE, J.L.; GOMES, P.C.; OLIVEIRA, R.F.; LOPES, D.C.; FERREIRA, A.S.; BARRETO, S.L.T.

Tabelas brasileiras para aves e suínos: composição de alimentos e exigências nutricionais. 3.ed. Viçosa: Universidade Federal de Viçosa, 2011. 185p.

SALEHA, A.A.; MYAING, T.T.; GANAPHATY, K.K.; ZULKIFLI, I.; RAHA, R.; ARIFAH, K. Possible effect of antibiotic-supplemented feed and environment on the occurrence of Multiple Antibiotic Resistant Escherichia coli in Chickens. International Journal of Poultry Science, v.8, n.1, p.28-31, 2009.

\section{SCHMIDT, E.M.S.; LOCATELLI-} DITTRICH, R.; SANTIN, E.; PAULILLO, A.C. Clinical pathology in poultry - A tool to improve poultry health - a review. Archives of Veterinary

Science, v 12, n.3. p.9-20, 2007.

SHAHIDI, F.; NACZK, M. Food phenolics: sources, chemistry, effects and applications. Lancaster: Technomic Publishing Co., 1995. p.235-273.

SILVA, J.D.T.; DIAS, L.T.S.; MACHADO, C.R.; CARVALHO, M.R.B.; RIZZO, P.V. Low tannin sorghum utilization in broilers feed.

Nucleus Animalium, v.1, n.2, p.39-52, 2009.

SILVA, M.P.; PESSOTI, B.M.S.; ZANINI, F.S.; COLNALGO, G.L.; NUNES, L.C.; RODRIGUES, M.R.A.; FERREIRA, L. Essential oil from Brazillian red pepper as an additive in broiler diet. Ciência Rural, v.41, n.4, p.676-681, 2011.
SIQUI, A.C.; SAMPAIO, A.L.F.; SOUSA, M.C.; HENRIQUES, M.G.M.O.; RAMOS, M.F.S. Óleos essenciais - potencial antiinflamatório.

Biotecnologia, Ciência e

Desenvolvimento, v.16, p.38-43, 2000.

SOUZA, L.F.A.; ARAUJO, D.N.; ASTOPHI, J.L.L.; DIAS, L.B.M.; AMBILL, A.C.; SANTOS, L.S.; CARMO, A.J.; SILVA, P.C.G. Probiotic and antibiotic as growth promoter for broilers. Colloquium Agrarial, v.6, n.2, p.33-39, 2010.

TEIXEIRA, A.S. Alimentos e alimentação dos animais. 5.ed. Lavras: UFLA/FAEPE, 2001. 241p.

TOLEDO, G.S.P.; COSTA, P.T.C.; SILVA, L.P.; PINTO, P.; FERREIRA, P.; POLETTO, C.J. Performance of broilers fed diets added of antibiotic and phytoterapic isolated or associated. Revista Ciência Rural, v.37, n.6, p.1760-1764, 2007.

TRAESEL, C.K.; LOPES, S.T.A.; WOLKMER, P.; SCHIMIDT, C.; SANTURIO, J.M.; ALVES, S.H.

Essential oils as substitutes for antibiotic growth promoters in broilers: soroproteins profile and lipid peroxidation. Ciência Rural, v.41, n.2, p.278-284, 2011.

\section{UBABEF. Associação Brasileira de} Exportadores de Frango. Disponível em:

$<$ http://www.abef.com.br/noticias_portal/ exibenoticia.php?notcodigo $=1708>$.

Acesso em: 19 fev. 2013.

UNIVERSIDADE FEDERAL DE VIÇOSA - UFV. Manual de utilização do Programa SAEG. Versão 8.0. Viçosa, MG: Fundação Arthur Bernardes, 2007. 
ZANINI, S.F.; COLNAGO, G.L.;

GONÇALVES F.G. Evaluación del

nível de inclusión de salvado de aroeira-

roja (Schinus terebinthifolius Raddi) en

la dieta de pollos de engorde. In:

CONGRESSO LATINOAMERICANO

DE AVICULTURA, n.11, 2009, Cuba.

Anais... Cuba, 2009.

ZANINI, S.F.; SILVA, M.P.;

PESSOTTI, B,M.S.; COLNAGO, G.L.;

NUNES, L.C., RODRIGUES, M.R.A.

Suplementação de vitamina E e/ou de óleo essencial de aroeira na dieta de frangos de corte sobre o desempenho e morfometria intestinal. Archives of Veterinary Science, v.16, n.2, p.76-81, 2011.

Data de recebimento: 10/04/2013

Data de aprovação: 07/02/2014 